\title{
LOS NOMBRES DE LOS “CUERPOS CELESTES" EN LOS ATLAS LINGÜÍSTICOS HISPÁNICOS
}

\author{
Josefa $M^{a}$ Mendoza Abreu
}

\begin{abstract}
Taking as starting point the linguistic atlas, the different forms used in Spanish to designate the more known celestial bodies are studied, serving that, in some way, as a guide for men in their different activities: the Great Bear, the Milky Way, the Morning Star and the Evening Star. It is observed that next to simple forms that partly continue the classic words as "Osa", "Carro" (Great Bear), "Lucero" (Venus), etc., most of the denominations respond to metaphorical processes that reflect the relationship between these celestial bodies and particular aspects of the human life; proceeding so much from their material environment as from the spiritual area or beliefs. Thus, we have "Carro triunfante", "Carro del cielo", "Carro pastor", etc., for the Great Bear; "Camino de Santiago", "Carretera de Santiago", "Camino de los uveros", etc., for the Milky Way; "Lucero de la mañana", "Lucero matagañanes", "Lucero miguero", for the morning star; "Lucero de la noche", "Estrella del poniente", etc., for the evening star. The different denominations depend sometimes on the several dialects and other times on various cultural and social aspects.
\end{abstract}

Cuenta la tradición que presidiendo Alfonso $\mathrm{X}$ una reunión de astrónomos, fundamentalmente árabes, pertenecientes a la Escuela Toledana, que habían sido invitados por él para confeccionar una nuevas tablas astronómicas, las conocidas después como Tablas Alfonsíes, quedó tan atónito al ver la complicación de esferas y movimientos que eran necesarios establecer para explicar la marcha de los astros, que no pudo menos que exclamar que si Dios le hubiese llamado cuando creó el mundo, le hubiera aconsejado mayor sencillez en su organización. $^{1}$

Si ello era así para un sabio, para el hombre común el entramado mundo celeste, con tantas constelaciones, tantas estrellas, ha resultado desde siempre más difícil de asimilar. De manera que sólo aquellos elementos, aquellas estrellas que de alguna manera afectan a su mundo particular (le indican, por ejemplo, cuándo tiene que sembrar, hacia dónde tienen que navegar o en qué momento sus animales van a parir) ${ }^{2}$ tienen interés para él y consi-

\footnotetext{
${ }^{1}$ J. Comas Solá (1942)

${ }^{2}$ San Isidoro, al explicar algunos de los nombres de los cuerpos celestes, y las causas por las que se les han impuesto, señala que las constelaciones se llaman así porque sirven de guía a los marineros que las observan para pilotar sus naves, y a todos en general, según su situación y brillo les indica como será el tiempo en determinadas estaciones: "Sidera dicta, quod ea navigantes considerando dirigunt ad cursum consilium, ne fallacibus undis aut ventis alibi deducantur. Quaedam autem stellaeidcirco signa dicuntur, quia ea nautae observant in gubernandis remigiis, contemplantes aciem fulgoremque eorum, quibus rebus status caeli futurus ostenditur. Sed et omnes homines ea intendunt ad praevidendas aeris qualitates per aestatem et hiemem vernalemque temperiem. . Ortu enim vel occasu suo certis stationibus temporum qualitatem significant." (vol I, p 474).
} 
guientemente serán esas las que tratará de conocer y reconocer. Pero para conocer hay que poner un nombre. Y para ello nada más claro que la comparación con algo familiar, ya sea del mundo real, o procedente del mundo de la mitología, de las creencias. De manera que los procesos metafóricos son y han sido desde siempre un factor que con bastante frecuencia ha influido en la denominación de los cuerpos celestes ${ }^{3}$.

Ello no quiere decir que sea sólo el hombre de la calle el encargado de denominar a estos elementos, entre otras cosas porque el ojo humano no puede percibirlos todos y por tanto será el científico con los instrumentos adecuados el que cumpla también esta función. Sin embargo las diferencias en este campo no son especialmente sensibles ${ }^{4}$, como puede comprobarse, por ejemplo, en los nombres del zodiaco (de todos conocidos) o en el de las constelaciones extrazodiacales boreales y australes propuestos por Ptolomeo 5 . Muchos de estos nombres han permanecido hasta hoy, ya sea con la forma puramente latina, es decir como cultismos, o bien con evolución patrimonial; otros han sido sustituidos por formas más acordes y más "significativas" de acuerdo con los cambios culturales y sociales producidos a lo largo de la Historia. Un ejemplo revelador al respecto puede ser el de la Vía Láctea, poco transparente ya para el hombre medieval, ${ }^{6}$ frente a lo significativo que podía resultar "Camino de Santiago", al servir de orientación a los peregrinos de Europa en sus viajes al sepulcro del Apóstol.

Veamos las diferentes formas que algunos de ellos ofrecen actualmente, a través de los distintos Atlas lingüísticos: ALEA, ALEICan , ALEARN, Cantabria y ALBI (Ni el de Colombia ni el de Méjico tratan el tema).

La Osa Mayor (ALEA, m. 838; ALEICan, m. 754; ALEANR, m. 1318; Cantabria, m. 47; ALBI, m. 68).

El DRAE la define, s.v. osa como:

\footnotetext{
${ }^{3}$ Ya el astrónomo J. Kepler dividio los nombres de las estrellas en dos clases principales. a) los surgidos por la semejanza sugerida con la configuración de los grupos; b) los que respondían a la estación del año en que aparecen o se ponen y la influencia de esta estación sobre las vidas de los marineros o los labradores. Añade E. J. Webb (1957: 35) que otro de los factores determinantes ha sido el deseo de distinguir algunos miembros honrados del género humano.

${ }^{4}$ Últimamente el interés por la observación de los cuerpos celestes es cada vez mayor, lo que propicia la proliferación de libros de divulgación sobre el tema donde se mezclan voces de diverso origen, generalmente voces cultas, "traducciones" y algunos arabismos. Vid. Velasco, E. y Velasco, P., 1999.

${ }^{5}$ Así: 1. Osa Mayor; 2: Osa Menor; 3: Dragón; 4: Cefeo; 5: Arador; 6: Corona boreal; 7: Arrodillado; 8 Lira; 9 Ave; 10 Casiopea; 11 Perseo; 12 Cochero; 13 Portador de la serpiente; 14 serpiente; 15 Flecha; 16 Aguila; 17 Delfín; 18 Parte delantera del caballo; 19 Caballo; 20 Andrómeda; 21Triángulo; 22 Ballena; 23 Orión; 24 Río; 25 Liebre; 26 El perro; 27 Predecesor del Perro; 28 Argos; 29 Serpiente marina; 30 Copa; 31 Cuervo; 32 Centauro; 33 Bestia; 34 Incensario; 35 Corona del Sur; 36 Pez Austral.

${ }^{6}$ En cualquier caso, este conjunto de estrellas que divide la bóveda celeste en dos partes casi iguales ha sido uno de los grandes misterios que las diferentes culturas han tratado de explicar y consiguientemente denominar a su manera. Para los griegos y romanos era la leche que se le derramó a Juno al dar de mamar a Hércules. Los indios precolombinos lo consideraban el sendero por donde transitaban los muertos; los chinos el río donde pescaba la luna, etc. (Paluzie Borrell, 1979: 507; E. J. Webb, 1957: 49; etc)
} 
"1. Astron. Constelación siempre visible en el hemisferio boreal, y fácil de conocer por el brillo de siete de sus estrellas, cuatro que forman cuadrilátero, y las otras tres un arco de círculo que parte de uno de los vértices del mismo cuadrilátero, semejando en conjunto un carro sin ruedas." (el subrayado es nuestro).

Efectivamente son estas siete estrellas principales (las siete más brillantes, y visibles por tanto a simple vista, de las 227 que forman la constelación. Desde antiguo contaban con nombre propio, aunque la más importante era, y es, Mizar, el 'abraçador' ${ }^{7}$, y también la forma que su ubicación dentro de la constelación parece dibujar, la que ha influido de manera decisiva en su denominación desde tiempos lejanos.

Ya en la antigüedad los griegos la conocían fundamentalmente con dos nombres. Ptolomeo la llamaba A $\rho \chi \tau \tau_{\zeta} \mu \varepsilon \gamma \alpha \lambda \eta$ "Osa Mayor". Para Homero era simplemente La Osa ${ }^{8}$. Pero también el mismo Homero (en la Iliada) menciona para esta constelación el nombre de "A $\mu \alpha \xi \alpha$ " usado tanto en el sentido del Carro como en el del Arado. (J. Webb, 1957: 6970). Ciaro es que la figura que formaban las estrellas que la integraban no podía tener forma de osa u oso y de carro a la vez. ¿Cómo justificar entonces ambos nombres?. Parece que la figura de la Osa Mayor tal como aparece dibujada en el globo de Ptolomeo (y también en uno moderno) cubre un espacio mucho mayor y abarca más estrellas que las siete brillantes del Carro, lo que permitía más fácilmente dibujar un oso a partir de ellas. Pero, a simple vista, hay relativa unanimidad en cuanto que la figura que forman esas siete estrellas se parecen más a un carro que a una osa ${ }^{10}$.

Para los romanos (dada la influencia de la mitología griega sobre la romana) ${ }^{11}$ era igualmente La Ursa Maior, pero también los Septem Triones ${ }^{12}$. Y como se sabe, ha sido el nombre latino URSA el modelo utilizado en la mayoría de las lenguas europeas, directamente por evolución, o como préstamo o calco.

Sin embargo, no es Osa ni la forma compuesta Osa Mayor la denominación más común y popular en español, por lo menos en el español coloquial peninsular, a pesar de ser la

\footnotetext{
${ }^{7}$ Para éste y otros nombres, romances y árabes, de algunas de estas estrellas contamos con el estudio ya clásico de Tállgren (1925, 664-666), basado en la Astronomía alfonsí. Según ésta "las estrellas dela Ossa mayor son XXVII. \&.VIII. fuera de la forma. \& son todas nombradas." (fol. 19r).

${ }^{8}$ En femenino, igual que en la leyenda que la personifica como Calisto, la madre de la Osa Menor. Algunos autores piensan que el nombre simple se debería a que desconocía la Osa Menor, lo que no parece probable.

${ }^{9}$ Nebrija (1492) recoge: Amaxa. e. por la constelación del Carro.

${ }^{10}$ De hecho la osa se ha dibujado a lo largo de la historia unas veces mirando hacia un lado y otras hacia otro, en un momento las tres estrellas que forman el arco eran el cuello y en otras un alargado rabo del que carece de hecho el animal.

${ }^{11}$ Las imágenes y las leyendas de los dioses griegos están presentes en Roma antes (al menos desde el siglo VI a. C.) incluso que los préstamos literarios. Probablemente la razón habría que buscarla en el pueblo etrusco, de fuerte influencia helena. (Vid P. Grimal, 1973, vol. I: 191-197)

${ }^{12}$ Es decir los siete bueyes que se destinan para arar. Pero esta denominación era igualmente utilizada para la Osa Menor, lo que justificaría probablemente su desaparición, al menos con estos significados.
} 
única que recoge el DRAE en su vigésima primera edición. Los Atlas lingüísticos vienen a demostrar, según reflejan las respuestas de los mapas correspondientes, que Osa Mayor tiene escasa vitalidad, pues sólo se documenta en unos pocos pueblos repartidos por toda la geografía española, concretamente en dos andaluces (ALEA, Al 203, 205), dos canarios (ALEICạn, Gc 30; Hi 3), uno aragonés (ALEANR, Z 607) y dos cántabros (S 504, 208). Con mayor profusión se documenta en El Bierzo, pues la encontramos como respuesta única en 9 de las 24 localidades encuestadas. (lo que significa el 33\% de las respuestas).

La forma simple Osa apenas aparece. Sólo se ha recogido en dos poblaciones canarias (ALEICan, Tf. 40; Fv 1) y en una andaluza (con la variante onza) como segunda respuesta junto con Carro ${ }^{13}$. Por el contrario, en la mayoría de los Atlas lingüísticos, aparecen otras voces que reflejan mayor difusión que la recogida por la Academia, ya sea como forma simple, derivada, o bien formando parte de un compuesto, más o menos lexicalizado (No vamos a entrar a dilucidar ahora si se trata de una forma compuesta o de un sintagma nominal, etc.). Las diversas denominaciones recogidas han sido:

Carro, precedida o no de artículo ${ }^{14}$, es, como decíamos la denominación más usual en Andalucía; Aragón, Navarra y La Rioja; Cantabria. En El Bierzo sólo se registra en la tercera parte de las localidades y en la mitad de ellas alternando con Osa Mayor (desconocemos si esta alternancia conlleva valor sociolingüístico). En Canarias tiene aún menos uso, de manera que, grosso modo, podemos decir que es característica de la isla de Fuerteventura, mientras que en las demás apenas se utiliza (El informante de La Graciosa "sabía que otros le llaman carro", pero él respondió arao; y algo parecido ocurrió en GC 3, como después veremos). En un pueblo cordobés, Co 202, encontramos el plural los carros. Nada nos dicen los autores del ALEA en relación con esta respuesta, pero la pregunta es obvia ¿se estarían refiriendo a las dos Osas?. No parece que haya otra explicación más aceptable.

El ara(d)o: En las Canarias, como acabamos de ver, aunque se conoce el vocablo carro, con más frecuencia se usa la voz arado ${ }^{15}$ para referirse a la Osa Mayor. Es la forma dominante en La Graciosa, Lanzarote, Hierro, mientras que supone un tercio de las respuestas de las islas mayores Tenerife $(2,20,31,6)$ y Gran Canaria $(11,4,40)$. Duplicidad de respuesta

\footnotetext{
${ }^{13}$ En Málaga 408 (Coín) registran los autores del ALEA una respuesta doble, la más general Carro y la más específica onza. Al estar en zona de ceceo, y dada su localización geográfica, podríamos interpretarla como un aragonesismo (onso) o tal vez como forma popular autóctona Vid. DECH s.v. oso.

${ }^{14} \mathrm{La}$ forma más habitual, precedida del artículo que lo singulariza, se da en andaluz y en $\mathrm{Lo}, \mathrm{Na}, \mathrm{Z}$ y Te, mientras que Huesca y Cantabria prefieren la forma sin artículo. Serían necesarios más datos de los que ahora tenemos para comprobar el valor de esta diferencia.

${ }^{15}$ También en Cuba, según parece indicar el Diccionario Vox, s.v. arado: "Cuba Constelación boreal". No lo recogen , sin embargo, los diccionarios de americanismos (Santamaría, 1942; Sánchez-Boudy, 1978; Morínigo, 1993). Por otro lado encontramos usada la voz arado para referirse a las 'tres estrellas' (Las tres más visibles de las Pléyades) en el Léxico de los marineros peninsulares (Alvar, M, 1985), como respuesta del segundo informante en Ge 1 (Roses). Y también en esta misma obra se documenta arao como el nombre de las Pléyades en GC 1 (Las Canteras) y en S 2 (Laredo). Es evidente que en Canarias, dada su latitud, ni la Osa Mayor, ni las Pléyades se ven de igual forma que en la Península, lo que puede llevar aún más a confusión, pero puede ser significativo que el nombre arado tenga también, aunque mínima, alguna vitalidad en territorio peninsular.
} 
arado, carro tenemos en LP 30; Tf 50, Fv 2, 20; en Go 3 el orden fue carro, arado. Y también aquí cabe preguntarse cual es el valor de esta duplicidad, es decir si son sinónimos totales o, como creemos, el orden en las respuestas conlleva al menos diferencias de uso.

Otras voces se documentan en los atlas, aunque son de localización más concreta, y habría que explicarlas por cambios producidos probablemente en épocas más tardías y debido a procesos particulares relacionados en muchas ocasiones con la propia historia cultural de cada zona. Así,

Cabrillas en ALEICan, GC 3 (Mogán) es forma un tanto sorprendente al ser una de las denominaciones más comunes para la Pléyades ${ }^{16}$, pero segura, según nos indica el prof. Alvar. En el ALEA se documenta también las cabrillas con este significado en una localidad muy concreta y con gran relación con Canarias, H 502 (Moguer) ${ }^{17}$.

El arca en ALEICan, GC 12 (S. Nicolás). Su escasa documentación nos hace más difícil determinar su posible origen. Con frecuencia los textos medievales, desde Alfonso X, hacen referencia a la infanta Parrasis y a su hijo el rey Archas y cómo fueron convertidos en estrellas, concretamente las dos estrellas que están delante del carro ("y el fijo que sigue delante el carro se llama arctophilax o se dize boetes: o el primer su nombre Archas": Palencia, A, 29r.). No conocemos ningún ejemplo castellano de este nombre referido a la Osa Mayor anterior a la conquista de Canarias (aunque tampoco de arado). Y también parece extraña la conservación del antropónimo mitológico sólo en este lugar. Por lo que resulta más lógico pensar en un cambio metafórico que vendría motivado por el significado de 'barca', 'especie de nave o embarcación' que esta voz tuvo desde época temprana ${ }^{18}$.

Carreta en ALEICan, GC 2 (Las Palmas). El DRAE recoge dos significados de esta voz:

"1. f. Carro largo, angosto y más bajo que el ordinario, cuyo plano se prolonga en una lanza en que se sujeta el yugo. Comúnmente tiene solo dos ruedas, sin herrar".// 2. "Carro cerrado por los lados, que no tiene las ruedas herradas, sino calzadas con pinas de madera". Y cualquiera de ellos puede ser el que motivara la comparación y consiguientemente la denominación $^{19}$. Aunque también podría tratarse de un portuguesismo más en Canarias, pues en portugués carreta es también la "Designação popular da Ursa Maior" (Figueiredo, 1996, s. v. carreta 4$)$.

\footnotetext{
${ }^{16}$ Aunque no exclusiva de ellas, de modo que, por ejemplo, cabrito es la traducción del nombre árabe de la estrella Polar; los dos cabritos el de dos estrellas de la constelación de la Auriga, etc. (Tállgren, 1925: 663 y 676 respectivamente).

${ }^{17}$ Ello no implica que los informantes no puedan estar equivocados, incluso en ambos casos. En el ALEA, al no existir la pregunta sobre esta constelación no podemos saber la denominación dada para ella en ese lugar. En Canarias parece que el hablante estaba muy seguro de que se trataría de un sinónimo de Carro.

${ }^{18}$ Según refleja el Léxico de los marineros peninsulares, en algunos pueblos portugueses (Port 2, 3, 8) la Osa Mayor recibe el nombre de barca (Alvar, 1985: 498). Y para los pastores del Canigó las cuatro estrellas que forman el Cinturón de Orión (parecidas a las cuatro del Carro) es el Arca de Noè (Amades, J., 1982, vol. I, 84).

${ }^{19} \mathrm{Nada}$ en especial nos dice de esta voz el Tesoro lexicográfico del español en Canarias.
} 
La galera fue junto con el carro la respuesta en ALEANR, Hu 302 (Angüés). Si entendemos que galera está utilizada con el significado de "Carro para transportar personas, grande, de cuatro ruedas, ordinariamente con cubierta o toldo de lienzo fuerte" (DRAE, s.v., $1^{\text {a }}$ ac.), parece claro que también aquí estamos ante un caso de sinonimia. Es más, las cuatro ruedas de la galera, actualmente, tienen más parecido con las cuatro estrellas que forman el cuadrilátero que las dos del carro ${ }^{20}$.

Las parejas en ALEA, Al 602 (San José). El DRAE, s.v. pareja 7 dice: "Arte de pesca compuesta de dos barcos que arrastran una red barredera de profundidad.". Creo que tratándose de un pueblo marinero esta denominación podría explicarse partiendo del significado marinero aplicado a los dos Carros ${ }^{21}$. También existe la posibilidad (aunque mucho más dudosa) de que estemos ante la traducción del nombre de dos de las estrellas de esta constelación denominadas en árabe Alcarayn 'pareios o yguales' ("et dizen les otrossi; alcarayn. que q<u>i'er dezir; pareios. o yguales": Alfonso X, Astronomía, fol. 19 v; Tállgren, 1925: $663)$.

La pértiga en Cantabria, S 211 podría ser el resultado de un proceso metonímico, quizás comparable a la forma rabisa que con este mismo significado se documenta en la localidad pontevedresa de Panjón (Alvar, 1985)

Veleta aparece en Cantabria, S 201, e implicaría un proceso metafórico, pues, como se sabe, durante mucho tiempo La Osa Mayor sirvió de guía a los navegantes.

Junto a estas formas simples encontramos otras voces, derivados y compuestos generalmente de las precedentes. Entre ellas encontramos:

El carrito, el carrico: El derivado con sufijo de diminutivo en -it- $o$-ic- lo encontramos en Andalucía y Aragón . La forma en -ito aparece en la Andalucía occidental: H 603 (Bollullos), Se 307 (Sevilla), Co 401 (Montoro); mientras que carrico lo tenemos en Gr 501, Al 303 y de forma más usual en las provs. de Navarra $(203,402)$ y Zaragoza $(300,502,600)$. Como puede verse la extensión es reducida y ello por razones obvias, pues aunque el sufijo aquí parece tener connotaciones afectivas más que valor de diminutivo, siempre quedan "recuerdos" de este uso, lo que podría llevar a la confusión con el Carro pequeño u Osa Menor.

Mucho más abundantes que estos derivados son, como decíamos, toda una serie de formas complejas, generalmente sintagmas nominales constituidos por un sustantivo y un adjetivo, que permiten precisar más, o hacer más "significativo" un nombre, individualizarlo dentro de su especie, convertirlo en un nombre propio. Estas formas, en la mayoría de los casos funcionan y por tanto pueden considerarse como verdaderos compuestos. En el plano formal están constituidas siguiendo los mecanismos generales de composición que

\footnotetext{
${ }^{20}$ Claro que el concepto "carro" y consiguientemente la metáfora surgiría a partir del carrus galo, de cuatro ruedas, distinto por tanto del currus latino, antiguo carro de guerra de sólo dos. De esa manera se explica más fácilmente la comparación, sin necesidad de quitarle las ruedas al carro.

${ }^{21} \mathrm{E}$ incluso podría ser algo mucho más simple, una elipsis de "las parejas de Carros".
} 
utiliza la lengua, de manera que las creaciones más frecuentes son: a) las compuestas por el sustantivo, generalmente carro (también aparece estrella), seguido (o precedido) de un adjetivo (de lengua o de discurso) que lo especifica o determina; b) las formadas por sustantivo más "de" más sustantivo; c) las formadas por dos sustantivos enlazados por la copulativa "y" (u otra partícula con "valor aditivo").

a) Compuestos de sustantivo + adjetivo o adjetivo + sustantivo $^{22}$ tenemos diversas formas. En unas el adjetivo añade valor cualitativo; en otras cuantitativo, ya sea tamaño o cantidad:

El carro triunfante ${ }^{23}$ o trunfante, es el compuesto de este tipo más utilizado: ALEA, Gr 308, J 400, Gr 200 / Gr 201, Al 201, 204; ALEARN: Lo 101, 401, 300, 301; Cantabria: S $108,107,304,309,311,301,404,401,409$ (sin artículo) 502, 601; ALBI: S. Miguel de las Dueñas, Villaverde de la Abadía.

El carro triunfal ${ }^{24}$, variante formal de la anterior, pero, curiosamente, con menor vitalidad: ALEARN, Lo 400. Tanto una forma como la otra suponen un proceso de ampliación semántica motivado por factores de tipo religioso.

El carro grande: ALEA, Co 103; ALEARN, Z 304; el carro mayor ${ }^{25}$ : en Z 502 por oposición a carro pequeño que es la denominación en ese lugar de la Osa Menor.

Siete estrellas: es la designación dada en tres localidades tinerfeñas muy próximas Tf 3 (Los Silos), 30 (Icod), 4 (La Orotava); También la encontramos en La Gomera, ya sea el compuesto completo (Go 2: Vallehermoso) o en la forma elidida Las siete (Go 4: San Sebastián de la Gomera; Go 40: Alajero). Fuera de Canarias sólo la encontramos en una localidad de El Bierzo: Silván ${ }^{26}$. También este nombre plantea ciertas dudas, pues es uno de los más usuales para las Pléyades. Pero no es extraño dada su transparencia en relación con el objeto. Además no podemos olvidar que es esa una de las formas más utilizadas en Portugal (13 de las 22 respuestas a esta cuestión en el Léxico de los marineros peninsulares, Alvar, 1985), por lo que de nuevo podríamos estar ante un portuguesismo en Canarias.

\footnotetext{
${ }^{22}$ La colocación del adjetivo antepuesto sólo se da en el caso de los numerales, siguiendo la construcción general
del castellano.

${ }^{23}$ La Academia no admite actualmente esta forma carro triunfante, sin embargo tiene uso en nuestros clásicos; por ejemplo Lope, Góngora y Cervantes usan indistintamente esta forma y la derivada del adjetivo, triunfal, aunque con el significado académico de este último.

${ }^{24}$ En el DRAE, s.v. carro se recoge: triunfal. 1. "carro grande con asientos, pintado y adornado, que se usa en las procesiones y festejos".

${ }^{25}$ Con el mismo adjetivo que Osa. Como después veremos, es el compuesto que aparecía en las ediciones anteriores del DRAE, del DUE. Actualmente lo recoge el Diccionario Vox, s.v. carro: Carro Mayor o simplemente carro, Osa Mayor. Y también el que tenía en griego. Sin embargo, la escasa localización en los atlas (aparece también en Castro Urdiales: Alvar, 1985) demuestra ahora un uso reducido.

${ }^{26}$ Allí a la Osa Menor la llaman Carrillín
} 
Los tres reyes: en Cantabria, S 306 (Bárcena Mayor) sí es más extraño, tanto por ser uno de los nombres más utilizados para las tres estrellas que forman el cinturón de Orión, como por la presencia del número tres en el compuesto. Sin embargo, para el Cinturón de Orión aquí se prefiere las tres marías (en pueblos de alrededor los tres reyes), por lo que la distinción queda asegurada.

b) Compuestos de sustantivo + de + sustantivo: ${ }^{27}$

El carro (de) Santiago: ALEARN: Z 201, Hu 401; y más frecuente sin artículo, Carro Santiago: ALEARN: Na 600, Hu 407, Hu 110, Hu 103, Hu 107

El carrico Santiago: ALEA, Gr 501, Al 303; sin artículo, Carrico Santiago: ALEARN: Te 300

El carro del cielo, ALEA: J201; ALEARN: Te 601

Carrico de Dios: ALEARN, Na 401

Carro de San Juan: ALEARN: Z 604

Carro de San José: Cantabria: S 310

Carro de San Antonio: ALBI, Páramo del Sil

Carro pastor: aparece sólo en ALEARN, Z 301; aunque algunas investigaciones la señalan como una de las formas más usuales. Su forma primitiva posiblemente sería "carro del pastor", igual que ocurre con formaciones similares como "estrella del pastor", etc., en las que igualmente se ha perdido la preposición. Aunque también podría pensarse en otra partícula, como "con", según veremos más adelante.

Carrelón del norte: ALBI, Sancedo. Es posible que "el norte" aquí esté usado como sinónimo de cielo. ${ }^{28}$

c) Compuestos de sustantivo + partícula +sustantivo:

Un grupo especial de formas está constituido por dos sustantivos (a los que puede preceder algún determinante) unidos por las partículas "y", "con", "de" que aportan diferentes matices $^{29}$. Así:

El carro y las mulas: ALEA, H 301, Co 301, Co 608; ALEARN, Hu 203;

Carro y las mulas: ALEARN, $\mathrm{Na} 400, \mathrm{Te} 206, \mathrm{Te} 403$

\footnotetext{
${ }^{27}$ Este segundo sustantivo pertenece casi siempre a un ámbito significativo muy concreto relacionado con la vida espiritual, concretamente suele ser el nombre de un santo, de Dios, etc.

${ }^{28}$ De todas formas, también aquí a la Osa Menor se le dice Carrilin o carrillin, por lo que el elemento diferenciador que sirve para mantener la oposición realmente es el sufijo del sustantivo carrelón / carrilín.

${ }^{29}$ No vamos a entrar a determinar si las preposiciones son o no elementos vacíos de significado. Incluimos aquí algunas construcciones con la preposición "de" porque pensamos que vienen a ser variantes formales que no modifican esencialmente el significado general del compuesto
} 
Carro con mulas : ALEARN, Z 400

Carro con tres mulas : ALEARN, Z 202

Carrito de mula: ALEA, Se 307 (Sevilla). Es el único caso en el que un compuesto de este tipo se registra en un núcleo urbano.

Carro de las cuatro mulas: ALEARN, Te 301. No sabemos cómo han surgido "las cuatro mulas". Es posible que en algún momento haya podido influir la presencia de otra estrella, de brillo mucho más débil, Alcor, que acompaña a Mizar, la más brillante de "las tres mulas" 30 .

Carro con el cabezón: en Cantabria, S 213 . En este caso las tres estrellas representarán al "cabezón", voz que debe estar usada con el significado de 'lanza del carro' tal como se recoge en algunas zonas occidentales (Miguélez, 1993, s.v.).

Arado con gañán: ALEICan, Hi 1, 10. Vendría a ser el paralelo canario de "carro (del, con) pastor"

Como se observa fácilmente los "triones" o los "bueyes" han desaparecido, siendo sustituidos en todos los casos por "mulas" que pasó a ser el animal de tiro por excelencia.

En ningún caso hemos encontrado los nombres de cacerola o cucharón con los que últimamente parece que se les quiere comparar (probablemente porque para muchos "carro" es ya poco significativo)

\section{Distribución dialectal}

Como hemos podido observar contamos con formas comunes a todo el dominio estudiado, como es el caso de carro, que claramente se refleja como la denominación más común, excepto en Canarias, que, en líneas generales prefiere arado. En las formas compuestas no se observan diferencias sensibles. Predomina El carro triunfante que aparece también en todos los atlas, con la excepción esperable de Canarias. Si matizamos por regiones, vemos que en Andalucía, en general, domina la forma simple. En las compuestas se observa una cierta diferenciación, de manera que la occidental prefiere el carro y las mulas (con las distintas variantes), mientras que la oriental utiliza construcciones referidas a un mundo más espiritual: carro triunfante, carro (carrico) de Santiago, de Dios, del cielo, etc. coincidiendo con el resto de los dominios dialectales. En el ALEANR también se dan ciertas diferencias, de manera que, por ejemplo, el carro triunfante aparece sólo en La Rioja, coincidiendo con Cantabria y el Bierzo, mientras que las otras provincias prefieren el carro de Santiago, etc.

\section{Documentación literaria:}

El DRAE hasta su vigésima edición, s.v. carro incluía en la novena ac.: " n. p. m. Astron. Osa Mayor". Y en los compuestos incluía: "Carro Mayor. n. p. Osa Mayor”. Carro

\footnotetext{
${ }^{30}$ De hecho, la mitología helena suponía un Carro de cuatro ruedas con cuatro mulas.
} 
triunfal, carro grande con asientos, pintado y adornado, de que se usa en las procesiones y festejos". Pero en la última edición ha desaparecido para carro el significado de Osa mayor (en su lugar aparece "tanque de guerra") y también los compuestos Carro Mayor, Carro Menor. Lo mismo ha ocurrido en el DUE de $\mathrm{M}^{\mathrm{a}}$ Moliner, en la $1^{\mathrm{a}}$ edición s.v. carro aparece: Nombre popular de la "Osa Mayor». También se dice «CARRO MAYOR» a la "Osa Mayor» ỳ «CARRO MENOR» a la «Osa Menor». En la $2^{\mathrm{a}}$ edición desaparecen ambos.

Sin embargo, ya desde Alfonso X, además de Osa mayor, se utiliza Carro en el romance para referirse a esta constelación, continuando así el nombre antiguo, según nos indica el propio rey: "Otrossi los dioses tanto fueron de grand piedad que a ycario \& a su carro que los non quisieron alli dexar trasladaron los suso al çielo con sus bueys. \& de Ycario e de sus bueys fue fecho e nombrado el signo a que dezimos Bootes ...\& del carro fizieron otrossi el signo que dizen del carro. \& llamanle en latín Plaustrum. \& plaustrum es esso mismo que carro en el lenguage de Castiella". Y sigue más adelante "...\& fincol otrossi su nombre antigo. Ca todos clerigos e legos le llamamos el carro q(u)ando nombrar queremos aquellas estrellas". (General Estoria, 271r).

Nada nos dice Nebrija al respecto (ni de carro ni de osa). Pero sí A. de Palencia quien nos explica la causa del nombre con una curiosa descripción que no deja de sorprender, pues redistribuye la ubicación de las estrellas: Arctos mayor [...] y ella es llamada carro por la semeiança del. Ca las cinco estrellas están por carro. Et las dos que parecen en vn logar son auidos por bueys ...". También para Covarrubias se trata de un carro de bueyes: "Cerca de los astrónomos es una constelación o cierto número de estrellas cercanas al polo ártico, que entre otros muchos nombres que tienen, le dan los griegos éste $\mathrm{A} \mu \alpha \xi \alpha$, quod plaustrorum similitudinem referant; y a una estrella que está cerca llamaron el carretero, porque parece irla siguiendo, dicho arctophilax [...] Por otro nombre Bootes, que vale tanto como el boyero; presuponiendo que el carro que sigue es de bueyes".

Lo mismo encontramos en Oudin (que en estos casos suele copiar a Covarrubias),, s.v. carro: "Le chariot qui est un certain nombre d'estoilles pres du Pole."

A pesar de la afirmación alfonsina (clerigos e legos), el término ha tenido diferente consideración social desde antiguo, de manera que encontramos algunos autores para los que carro es de uso popular. Así lo vemos, por ejemplo, en el Vocabulario Eclesiástico de Fernández de Santaella: "Arturus ... las siete estrellas cerca el norte que llaman el carro los vulgares. \& los astrólogos vrsa mayor.” (fol. 17r.) ${ }^{31}$.

En esa misma línea se muestra el Diccionario de Autoridades, que, en la tercera entrada de carro, nos dice: "Se llama vulgarmente la Constelación que los Astrónomos llaman Ursa ù Ossa Mayór. Lat. Arctos Cynosura ${ }^{32}$. Fr. L. de GRAN. Symb [...] . Además explica el origen del nombre, o mejor dicho de los nombres, introduciendo un sinónimo no docu-

\footnotetext{
${ }^{31}$ Claro que podemos interpretar "vulgar" como la persona no especialista en la materia, aun así supondría una apreciación distinta a la alfonsina.

${ }^{32}$ Aunque Cynosura era el nombre de la Osa Menor
} 
mentado: "Vienen a hacer ciertas figuras por las cuales son nombradas: como el carro, la bocina y otras semejantes, que son guías de los que navegan por la mar. [...] Pero todos concuerdan en llamarla [a la Ursa Mayor] carro o coche.". Nada sabemos de esta última denominación, $\operatorname{coche}^{33}$. En cuanto a la bocina, a la que se refiere Autoridades como "nombre dado por los marineros a la Osa Menor", es evidente que al menos antes debía de ser de uso más general ${ }^{34}$. De esa manera se explica la amplia difusión de Carro como forma simple, pues la oposición sería carro / bocina y no a través de los adjetivos mayor / menor.

Y Carro o Carro mayor se sigue documentando hasta hoy, en la mayoría de los diccionarios sin calificación dialectal o social (Terreros, Roque Barcia, Vox, etc.).

En cuanto a las otras formas son mucho más difíciles de documentar, pues no aparecen en los diccionarios históricos, ni en los dialectales usuales.

La Vía Lactea (ALEA, m. 839; ALEICan, m. 756; ALEANR, m. 1320; Cantabria, m. 49; ALBI, m. 69).

El DRAE s.v. vía recoge el compuesto culto Vía Láctea con el siguiente significado:

"1. Astron. Ancha zona o faja de luz blanca y difusa que atraviesa oblicuamente casi toda la esfera celeste, y que mirada con el telescopio se ve compuesta de multitud de estrellas".

Sin embargo, al igual que veíamos antes, los mapas lingüísticos indican que el cultismo es poco habitual. Ni una sola vez se documenta en el ALEA, en el ALEICan, o en el Atlas de Cantabria. En el ALEARN se registra en Hu 100 (Sallent de Gállego) junto con otra respuesta, camino de Santiago; mientras que en el ALBI aparece dos veces, como única respuesta en Vega de Yeres y junto con Camino de Santiago en Igüeña.

Frente a esta ausencia casi generalizada de Vía Lactea (que no implica necesariamente el desconocimiento del término, sino probablemente sólo la falta de uso) encontramos toda una serie de sintagmas o formas compuestas que en parte parecen un calco del latín, pues casi todas están formadas con un primer elemento que pertenece al mismo campo semántico que "via", como son "camino", "carrera", "carretera", "carril" o "vereda", seguidas de un adjetivo que lo especifíca. Y es que probablemente una "motivación" similar a la que originó en latín Vía llevó al castellano a la utilización de esas otras formas, posiblemente más usuales ${ }^{35}$.

Las formas encontradas son:

\footnotetext{
${ }^{33}$ Es posible que estemos ante una identificación con otra constelación, la del Cochero.

${ }^{34}$ Recordemos los versos de Góngora: "Es hombre que gasta / En astrología /.... Conoce muy Bien / Las siete Cabrillas, / La Vocina, el Carro / I las tres Marías". Algo similar vemos en Lope, en El galán de la Membrilla (159): "Ya del primer arrebol / cubriendo el alba se va/ Veré el Carro y la Bozina". Y como tal aparece actualmente en el DRAE, s.v. : 8. n. p. Osa Menor.
}

${ }^{35}$ Sobre las limitaciones semánticas de "vía" y su sustitución por "camino", vid. DECH s.v. vía. 
Camino de Santiago: es la denominación más común con que se la conoce. En el ALEA fue la única respuesta en las provincias de Jaén y Córdoba (excepto Co 605) y la más común en todas las demás (En H 401 -Campofrío- se dio también "Camino del Señor Santiago"). Fue también respuesta única en el ALEICan, aunque igualmente con alguna pequeña modificación en puntos concretos de la isla de Lanzarote, pues en $\mathrm{Lz} 1$ y 20 se dice "camino de San Santiago" y en Lz 4 uno de los informantes dijo además de "camino de Santiago", "camino de san Felipe Santiago" (no sabemos si pensando en los dos hermanos santos o rebautizando a Santiago). Lo mismo ocurre en Cantabria, donde "camino de Santiago" (con variantes fonéticas como -u final, etc.) es general salvo dos excepciones ( $\mathrm{S}$ $100,108)$, e incluso en El Bierzo, aunque aquí ya no de manera tan uniforme. El ALEARN muestra, sin embargo, mayor diversidad, dependiendo de las zonas, si bien, en líneas generales podemos decir que "camino de Santiago" domina en La Rioja, el centro-sur de la provincia de Zaragoza y la zona occidental de la de Teruel. En el norte de Huesca (Hu 200, 202) encontramos además la forma con apócope (considerada por Alcover y Moll como arcaica, pero que, según Corominas, pervive en algunas zonas del catalán occidental) camin de Santiago

Caminico de Santiago: es forma exclusiva de Navarra y Aragón: el ALEARN la recoge en $\mathrm{Na}$ 601, Za 501, 507, 602; Hu 301; Te 405, 601; y también en V100

Carrera de Santiago: El ALEA lo documenta en la provincia de Granada ( $\mathrm{Gr} 503,404)$. En el ALEARN en Lo 400, Lo 401, 601, 603, 604, 602, 600; Hu 304; Te 200. En el Bierzo encontramos la variante "carrero de Santiago" en Dehesas.

Carretera de Santiago: En el ALEA se recogió sólo en Se 300 y en Ma 401 (pero sabemos que se da también en otras poblaciones, por ej. Morón de la Frontera, aunque no aparezca así en el Atlas). En el ALEARN aparece en Lo 605; Na 205, 400, 401, 303 (con C. de S.); Z 100, 101, 200, 202, 300, 400; Te 200, 201, 203, 206, 403, 404, 407; y es casi general en la provincia de Huesca. En Cantabria sólo en S 108. No se documenta ni en canarias ni en El Bierzo.

Carril de Santiago: tiene cierta extensión andaluza, pues el ALEA lo recoge en H 501, $500,600,503,402$; Se 303, 308, 400, 602; Ca 100, 101, 102, 301, 302, 500, 201; Ma 203; Gr. 300, 504, 203. En el ALEARN sólo en Lo 305. En Co 605 se precisa además el compuesto, convirtiéndose en el carril del caballo de Santiago ${ }^{36}$, que explicaría la forma navarra, por elipsis, caballo de Santiago (Na 202).

Vereda de Santiago: Sólo aparece en el ALEA: H 602, Se 503, 600, 601, 603; Ca 200, 601.

Rodeira de Santiago: forma leonesa ('rodada'), aparece sólo en el Bierzo (Dragonte, Valverde de la Abadía).

${ }^{36} \mathrm{Y}$ es que en la creencia popular, como afirma el informante de $\mathrm{Na} 502$ (que responde Camino de S.) el "camino", o el carril, "lo marcó el caballo de Santiago cuando los moros" 
En la zona de habla catalana o de clara influencia de esta lengua, es decir el norte de la provincia de Huesca y la zona oriental de las de Huesca, Zaragoza y Teruel, encontramos las formas correspondientes, como Carretera de San Jaume ${ }^{37}$ (Z 606, Te 202, 205, 207) y Cami de San Jaume ${ }^{38}$ (Hu 602).

Aunque mucho más esporádicas, no faltan las construcciones en las que como segundo elemento encontramos el nombre de otro santo, generalmente San Pedro o San Juan:

Camino de san Pedro: ALEA, Ma 300

Camino de san Juan: ALEA, Al 600; ALEARN, Hu 300 (junto con Carretera de S. Juan) $)^{39}$

Camino del rey san Fernando: ALEA, Se 304 (Burguillos), supone una excepción, aunque en este caso la denominación probablemente sea debida a la especial relevancia que Fernando III ha tenido en Sevilla y alrededores como rey conquistador. De manera que la metáfora se referiría al "camino" seguido en las conquistas.

Carretera de san Pedro: ALEARN, Te 104, Cs 302

Carretera de san Juan: ALEARN, Na 204, Na $405^{40}$, Hu 404, Hu 300 (Junto con Camino de San Juan).

Frente a estas formaciones, resultado en parte de la influencia religiosa, tenemos otros compuestos que presentan la misma estructura en cuanto a su formación, mantienen incluso como primer elemento el vocablo más común camino, pero modifica el segundo, tomándolo de un campo semántico muy concreto, generalmente el de la vendimia ${ }^{41}$, que determina que el compuesto en conjunto se adscriba a una esfera mucho más terrenal en lo que al aspecto significativo se refiere. Así:

Camino, caminico (de) las uvas: ALEA, $\mathrm{Al}$ 202, 503. Camin las uvas: ALEARN, Hu 204

Camino, caminico de la uva: ALEA, Gr 510, $\mathrm{Al} 504$

Camino (de) los uveros, camino de las uvas: ALEA, Se 404

Caminico de las viñas: ALEA, Gr 505

\footnotetext{
${ }^{37}$ Prescindimos de las variantes fonéticas del antropónimo.

${ }^{38}$ Esa es la única forma documentada en Andorra (Griera, 1960, m. 384).

${ }^{39}$ Según el informante "porque pasaría san Juan".

${ }^{40}$ En este caso el informante justifica el nombre indicando que "se ve por San Juan".

${ }^{41} \mathrm{La}$ vendimia y todo lo que ella significa para el hombre puede verse reflejado en el nombre que desde muy antiguo llevaba y lleva una estrella de la constelación de la Virgen, Vindemiatrix, forma latinizada del antiguo

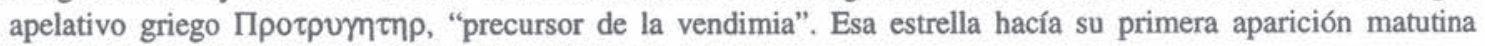
cuando se aproximaba la vendimia. (E. J. Webb, 1957: 61)
} 
Camino de Manzanares: aparece sólo en una localidad granadina (ALEA, Gr. 201 y notas) y también aquí se explica el nombre "porque anuncia la vendimia", según el informante. Además, los autores del Atlas nos indican que Manzanares era el pueblo manchego a donde iban a vendimiar la gente de esa zona.

Camino del infierno: ALEA, Ma 407. Responde probablemente a alguna tradición que desconocemos. Aunque tiene paralelos en otras zonas, como camí del diable en El Rosellón (Amades, J., 1982: 74)

Formas simples: En este caso son muy pocas las localidades en las que aparecen lexías simples y también muy reducido el número. Una de ellas es carretera (ALEARN, Na 106, Z 600), que sería un claro ejemplo de elipsis. Las otras son:

Surco: Cantabria, S 100. Probablemente sea una metáfora a partir de alguno de los significados de esta voz: "1. $\mathrm{m}$. Hendedura que se hace en la tierra con el arado. 2. Señal o hendedura prolongada que deja una cosa que pasa sobre otra." (DRAE, s.v.)

Madero: ALEARN, Na 404: que resulta de más difícil explicación. Podría pensarse en una comparación partiendo del significado 'viga de madera'.

\section{Distribución dialectal}

Como se ve hay una forma común a todas las zonas, camino de Santiago ${ }^{42}$ y otras que son usadas preferentemente en determinadas áreas. Así la forma con diminutivo caminico de Santiago es de uso navarro-aragonés y prácticamente lo mismo ocurre con carretera de Santiago, aunque ahora tenemos alguna localización andaluza. Por el contrario, las formaciones con carril y vereda se presentan como de uso preferentemente andaluz (la única excepción de Carril de Santiago está en la Rioja). Pero además Vereda de Santiago restringe su localización a las dos provincias marineras occidentales. También es curioso que las construcciones en las que como segundo elemento aparece un sustantivo que se incluye desde el punto de vista significativo en la esfera no espiritual, de nuevo son de uso preferentemente andaluz ${ }^{43}$.

\section{Documentación literaria}

En los Libros del saber de Astronomía, en el del "Ochavo cielo", describiendo la figura de la saeta y las estrellas que hay en esta constelación, se señala ya el nombre romance, siguiendo la tradición habitual de muchos textos alfonsíes:

"e son dentro en aq(ue)lla carrera $q(u e)$ paresçe de noche blanca enel çielo ellamanla en griego galaxia e en latin via latea q(ue) qujere diçir la carrera de la leche e algunos le diçen aca en n(uest)ro lenguaje ${ }^{44}$ el camjno de santiago e por eso le pusieron asi nombre porq(ue)

\footnotetext{
${ }^{42}$ Todos los romances, excepto el rumano poseen derivados del latín vulgar CAMMINUS.

${ }^{43}$ También "camino de las uvas" se documenta en una localidad próxima extremeña, Arroyo de San Serván (Viudas, A., 1980)

${ }^{44}$ En el códice de la Complutense aparece romançe
} 
es toda llena de estrellas menudas eson tantos dellas q(ue) non pueden ser contadas e son tan espesas e tan çerca una de otra q(ue) paresçe todo como blanco aq(ue)llos logares en que estan . E esta carrera destas estrellas ha muy gran v(ir)tud de que fablaremos ..." (fol $32 \mathrm{r}$ del Códice de la Academia de la Historia) 45 .

En este texto comprobamos además que carrera está utilizándose con el significado de "curso de los astros" (DRAE s.v. 3).

También Nebrija (1495) recoge Camino de Santiago en el cielo. Via lactea.

Para algunos se trata de una forma vulgar, como A. de Palencia (s.v. camino) quien habla de strada o camino como formas que utiliza el vulgo para referirse a la Via Lactea: "Gala en griego quiere dezir en latín leche y assi la zona del cielo que dizimos lactea bien se llama galathia la qual el vulgo llama strada o camino que faze señal blanca en el cielo". También Covarrubias comparte esa opinión, lo que le lleva a corregir a Nebrija: "Antonio de Nebrija puso en su diccionario: camino de Santiago en el cielo, via lactea, galaxias. Yo pienso que èl habló conforme a la intención del vulgo, y no en el rigor de la verdad. Nació la equivocación de que aquella mancha del cielo, que los físicos y los astrónomos dizen ser concurso de muchas estrellas de quinta y sexta magnitud, cuya luz se confunde una con otra, y causan aquel resplandor blanco, como de leche, que en griego se llama $\gamma \alpha \lambda \alpha[\ldots]$ se fueron con el sonido, camino de Santiago." ". En la misma línea se muestra Autoridades, que explica además el porqué del nombre: "Camino de Santiago. Llama el vulgo a la Via lactea, ó faxa que se vé en el cielo de noche , que parece tira de Norte a Sur, y la cáusa el reflexo de una multitud de estrellas, que por estar muy juntas se confunde la luz, y forman aquella claridad: por debaxo de la qual cree la ignorancia van los peregrinos à visitar al Apostol Santiago".

En cuanto a las otras denominaciones, Martín Alonso (1986) señala que también carretera aparece como sinónimo de Vía Lactea en los Libros del Saber de Astronomía. El problema está en que el dato procede de la edición de Rico y Sinobas. También el DECH indica que carretera ya significa 'camino' en Alfonso X, pero basándose en el Diccionario Histórico, por lo que tampoco es muy fiable. De carril y vereda no hemos encontrado documentación anterior en este sentido.

Venus-Lucero del alba (ALEA, m. 840; ALEICan, m. 755; ALEANR, m. 1319; Cantabria, m. 48; ALBI, m. 71).

Como es sabido, es este uno de los pocos casos en que el nombre varía o puede variar, dependiendo del momento en que se ve el objeto o mejor dicho el planeta. El fenómeno se daba ya desde la antigüedad clásica, de manera que cuando Venus aparecía por el este al

\footnotetext{
${ }^{45}$ Quiero expresar mi sincero agradecimiento al Dr. Rafael Cano Aguilar, que generosamente me facilitó sus propias transcripciones (aún inéditas) de los distintos manuscritos.

${ }^{46}$ Continúa con la leyenda que explica el nombre latino, concluyendo de forma particular: "Los poetas fingen ser leche que se le fue de los pechos a Juno, quando estando durmiendo le puso Júpiter a Hércules para que la mamasse, con que pudo deificarle, y atraxo tanta leche, que despertando Juno fue forçoso el derramarse por el cielo y de lo que cayó en la tierra sobre los lilios, se tornaron blancas açucenas.
} 
amanecer se le llamaba Phosphorus o Lucifer y cuando estaba situado al oeste al atardecer se le denominaba Hesperus. Esta misma diferenciación se da desde los primeros tiempos del romance, y así lo señala Alfonso X en la General Estoria, indicando también aquí los términos romances:

"Et es uen(us) no(m)bre de aq(ue)lla planeta cuya estrella paresce en un tie(m)po dell an(n)o enla tarde e(n)occident sobre espan(n)a. \& en otro tie(m)po en orie(n)te ala man(n)ana ante que nazca el sol. \& q(u)a nndoparesce en occide(n)te le dizen Esp(er)o. \& q(u)an`do enoriente el luzero." (fol. 39 r).

Nada encontramos en los atlas lingüísticos que confirme el uso popular de véspero en castellano (En el DRAE: 1. m. "El planeta Venus como lucero de la tarde"). Pero sí de Venus y de Lucero, que se conserva con los dos valores, aunque con diferencias de uso.

El DRAE, s.v. Venus señala: 1. n. p. m. "Segundo planeta del sistema solar que presenta un resplandor intenso y tiene fases similares a las de la Luna."; mientras que para Lucero ${ }^{47}$ nos da la siguiente definición: $1 . \mathrm{m}$. "El planeta Venus, comúnmente llamado la estrella de Venus.", distinguiendo en este caso los compuestos: "del alba, de la mañana o de la tarde. 1. lucero, planeta Venus.". De manera que en esta voz nos da , además de la forma culta, Venus, la que se supone más común "la estrella de venus" y también otras: "lucero del alba", "lucero de la mañana" y "lucero de la tarde", que es de suponer que también son de uso popular. Los mapas de los atlas lingüísticos nos dan esas y otras denominaciones:

Venus es, como era previsible, una de las formas menos extendida. De hecho sólo se registra en el ALEICan y en cuatro puntos concretos Fv 1,30 y Gc 2, 40

Lucero (precedido o no de artículo) lo encontramos en el ALEA en H 102, 402; Se 102, 307, 603, 503 (junto con matagañanes); Gr 602; J 101, 503, 308; Al 203, 205, 602. En el ALEICan aparece como forma única en la isla del Hierro, predomina en las de Tenerife (2, $20,21,30,3,31,41,5,6)$ y Lanzarote $(2,10,20,1,3)$; es la denominación de La Graciosa, y más esporádicamente la encontramos en Gran Canaria $(1,12)$, La Gomera $(3,40)$ y Fuerteventura (2, 20). El ALEARN en Lo 102, 300; Na 200, 105, 303, 307, 401, 403, 405; Za 200, 302, ; Te 201, 402; Cs 302 .

El aumentativo estrellón o estrelón es exclusivo del norte de Huesca ( $\mathrm{Hu} 100,101$, 102).

Mucho más frecuentes son también aquí las denominaciones a través de sintagmas nominales compuestos por sustantivo (que en algún caso puede elidirse) y adjetivo, con las estructuras:

a) lucero / estrella / estrellón + de + sustantivo

b) lucero / estrella / estrellón + adjetivo (simple o compuesto)

\footnotetext{
${ }^{47}$ Que muy acertadamente hace derivar de luz, como creación romance, pues, como señala el DECH,(s.v. luz), fonéticamente es imposible que derive de lucifer. De éste surgí lucífero ("El lucero de la mañana": DRAE s.v. 2), forma que no aparece en los atlas.
} 
Lucero del alba: en líneas generales se puede decir que es la forma predominante, aunque no en todas las regiones tiene el mismo uso, ni dentro de una misma zona dialectal. ALEA, H 202, 204, 504, 603; Se 304, 601, 403; Ca 100, 101, 102, 300, 601, 201, 204, 400; Co 104, 200, 202, 403, 600; Ma 500, 501, 203, 800; J 202, 300, 500; Gr 504, 402, 200; Al 202, 400, 507, 508. ALEICan, , Lz 4, Tf 4. ALEARN, es casi general en La Rioja y la forma más extendida en Navarra, Zaragoza y Teruel y en Hu 105,106, 108, 200, 403, 405, $304,305,603$.

Lucero del día: ALEA, H 300, 302, 500, 501, 203, 400; Se 602, 100, 600; Co 100, 101; Ma 100, 101, 102, 300, 304, 401, 404, 407; Gr 301, 302, 304, 401, 403, 404, 408, 410, 501, 502, 508, 513, 514, 604. Al 204, 301, 401, 404, 505, 601. ALEICan, LP 2; GC 3, 4; Lz 4. ALEARN, Na 106, Za 506; Te 103, 304, 30\%, 600; Gu 200; Cs 300, 301.

Lucero de la mañana: ALEA, Se 306; Ca 602; Co 102, 300; Ma 202; Gr 300, 407, 409, 600, 601, 505, 510, 512, 515; Al 201, 405, 502, 509. En el ALEICan: Lz 30; Fv 3; GC 11, GC 10 (con estrella de los gañanes). ALEARN, Na 102, 301; Za 505; Te 500, 406; Cu 200. Cantabria, S 202, 203, 201, 205, 204, 404, 405.

Lucero de la madrugada: ALEA, Se 404; J 102, 404, 307; Gr 406; Al 302, 503. ALEICan, FV 31. ALEARN, Te 306, 400.

Lucero del amanecer : Cantabria, S 107, 313, 503, 209.

Lucero al saliente: Cantabria, S 304

Lucero Venus: ALEA, Al 402, 403. ALEICan, GC40.

Lucero matagañanes: ALEA, H 201; Se 300; Ca 205. Aunque es mucho más frecuente la forma simple por elipsis matagañanes ${ }^{48}$ : ALEA, H 100, 101, 602, 502, 401 (con lucero del alba); Se 101, 302, 310, 500, 400, 402, 308, 406, 309 y 501 (con lucero del alba), 502, 503 (con el lucero); Ca 203, 204, 301, 302, 200 (con lucero del alba) 600 (con lucero del alba), 500 (con lucero del alba) ${ }^{49}$.

T. Garulo (1983: 92) llama la atención sobre la presencia de esta forma matagañanes "creación expresiva a partir de gañán, en un área bastante alejada de donde se localiza gañán 'vaquero': en la zona opuesta". Pero gañán significa también "Mozo de labranza" (DRAE s.v. 1). De hecho es el significado más general, el que tiene normalmente en el occidente andaluz ${ }^{50}$ y que permite igualmente la formación del compuesto.

Lucero miguero: El DRAE, s.v. miguero dice: "1. adj. Relativo a las migas; los pastores llaman al lucero de la mañana el lucero MIGUERO, porque hacen las migas cuando aso-

\footnotetext{
${ }^{48}$ Es probable que el proceso de la elipsis se haya visto favorecido por ser el adjetivo otro compuesto

${ }^{49}$ Pero en Ma 303 llaman matagañanes a dos luceros que acompañan al del alba.

${ }^{50}$ Coincidiendo con el señalado por Nebrija (1495): "gañán que ara. arator. oris". También este significado permite discutir el origen árabe de esta voz. Vid. DECH, s.v. gañán.
} 
ma". ALEA, Se 200, 401 (con lucero del alba); Co 601, 605; Ma 201, 202; J 200, 203, 205, 304, 305, 403, 504; Gr 201, 203, 500, 506, 511, 305 (con lucero del dia), 503 (con lucero del día), Al 501, 504, 506, 402, 509 (con lucero de la mañana), 200 donde añadieron lucero de la miga. En el ALEARN sólo en dos localidades cercanas dieron este término y en una en respuesta doble, "lucero del alba, lucero miguero" Z 602; Te 100.

Miguero: ALEA, Se 201; Co 301 (con lucero del dia); El miguero, el miguelo en Gr. 303; el pajero, el miguero en J 402. La forma simple, por elipsis, en este compuesto es menos frecuente que en el anterior. Y desde luego no tienen la extensión general que parece deducirse del DRAE.

Güeyero: donde suponemos un "lucero" elidido, aparece en ALEARN, Te 404

Lucero del labrador: ALEICan, Go2.

Tambien con "estrella" encontramos formaciones similares, aunque menos frecuentes:

Estrella del alba: ALEA, H 200, 303.

Estrella del día: ALEA, H 502; ALEICan, LP 1, 10, 20, 30 (es la forma predominante de la isla de La Palma); TF 40; Cantabria, S 305.

Estrella de clarear el día: ALEICan, GC 30

Estrella matutina: ALEARN, Z 301, Lo 502 (con lucero de la mañana)

Estrella del aurora: ALEARN, Hu 602

Estrella polar: Supone una evidente confusión (no sabemos si de nombre o de significado) en ALEARN, Na 203; Cantabria, S 403

Estrella del gofio: ALEICan, LP 3

Estrella de los gañanes: ALEICan, GC 10

Estrella jornalera: ALBI, Igüeña (en nota se dice que es la primera que nace y la primera que se quita)

Labradora: con elipsis de estrella en ALEICan, Go 4. Es la única excepción frente al general "lucero" (simple o compuesto) ${ }^{51}$ en esa isla.

La vaquera: ALEICan, Tf 50.

En una zona muy concreta, el dominio aragonés, aparecen las formas características de $\operatorname{masculino}^{52}$

\footnotetext{
${ }^{51}$ Antes veíamos "lucero del labrador" en Go 2.

${ }^{52}$ En el Léxico de los marineros peninsulares encontramos estrellon do día en C 5 (Lage, La Coruña), pero el informante estuvo en la guerra en Teruel -dato significativo- y ha viajado por todo el mundo.
} 
Estrellón del alba: ALEARN, es la forma peculiar y generalizada de la prov. de Huesca, sobre todo de la zona occidental y central

Estrello del alba: La forma de masculino, con mantenimiento o apócope de la vocal final -o domina el oriente de la prov. de Huesca. Estrello del alba en $\mathrm{Hu} 203,601,603$. Con apócope vocálica (la consonante final ofrece diferentes realizaciones palatal o velarizada) se recoge en Hu 201, 205, 401, 402, 404, 405, 408.

Estrel, estel del día: son variantes catalanas en Z 606, Te 205

Estrel bover [boßé]: Con la forma catalana ${ }^{53}$ en Te 202 (Calaceite, Teruel). Recordemos que muy cerca (Te 404) aparece también un lucero güeyero con el mismo significado.

Matacarreteros, estrello: fue la respuesta doble en Z 401, donde vemos una construcción similar al matagañanes de la Andalucía occidental (también sin documentación en el DRAE).

\section{Distribución dialectal}

A través de estos datos comprobamos lo que decíamos al principio, es decir la forma Venus es sumamente escasa, sólo aparece en Canarias. Lucero tiene ocurrencias en casi todo el dominio, aunque poco frecuentes. Por zonas observamos que la mayor extensión se da también en Canarias. Sin embargo no se documenta en Cantabria, y en el dominio navarroaragonés tiene su máxima extensión en Navarra frente a su total ausencia en la provincia de Huesca.. Por el contrario las formas compuestas son las más frecuentes. Sobresale lucero del alba, de extensión general, con la excepción de Canarias que prefiere la forma simple. Le sigue en importancia en cuanto al número de apariciones lucero del día también de uso general, esta vez con la excepción de Cantabria; sin embargo en Andalucía es más frecuente que el anterior. Lucero de la mañana tiene también extensión general, pero su mayor frecuencia de uso la tenemos en la provincia de Granada y en la mitad oriental de la de Cantabria. Los otros compuestos con Lucero y un sustantivo referido a momentos del día son más esporádicos. Destacan, sin embargo Lucero matagañanes y sobre todo la forma simple matagañanes exclusiva y dominante en la Andalucía occidental ${ }^{54}$, concretamente en Sevilla (18 resp. $/ 31=58 \%)$, Huelva $(6$ resp. $/ 24=25 \%)$ y Cádiz $(8$ resp. $/ 17=47 \%)$. Y Lucero miguero y más esporádicamente miguero son las formas características de las otras cinco provincias andaluzas, con dos ocurrencias sevillanas limítrofes con la prov. de Córdoba. Fuera de Andalucía sólo aparece en dos localidades aragonesas muy próximas Z 602 y Te 100 .

\footnotetext{
${ }^{53}$ Alcover y Moll, s.v. Bover 2. recogen "L'estel bover: el planeta Venus, que serveix de guia horària als pastors i bovaters" y también, como neologismo, es la denominación de "l' estel Artur o alfa de la constellació del Bover, que es pon a l'hora del crepuscle vespertr".

${ }^{54}$ Alcalá Venceslada, s.v. matagañanes dice: "Estrella Sirio. Lucero miguero.", lo que significa que desconocía la localización dentro de la región tanto de matagañanes como de miguero (a éste probablemente lo supondría general); pero además las identifica erróneamente con la estrella Sirio, que nada tiene que ver, pues se trata de una de las estrellas -la más brillante muchas veces- de la constelación del Can Mayor.
} 
Los compuestos con estrella son mucho más escasos. Lo más destacable es la presencia sistemática de las formas de masculino Estrellón o estrello, con variantes, como primer elemento, en la provincia de Huesca. Y quizás estrella del día por su extensión en la isla de La Palma, coincidente de nuevo con la andaluza H 502 (Moguer). Junto a ésta son localidades onubenses en la frontera las únicas andaluzas en las que encontramos estrella, y ello hace pensar inmediatamente en una posible influencia portuguesa. El Léxico de los marineros peninsulares (Alvar, 1985, vol. I: 493-95) refleja igualmente que las zonas encuestadas de habla catalana (toda Cataluña, Valencia y Baleares) y gallego-portuguesa (aquí sólo la prov. de La Coruña y casi todo Portugal) prefieren las formaciones con estrella, mientras el resto, o sea la zona castellana se inclina por los compuestos con lucero.

\section{Documentación literaria}

La primera documentación de Luzero la encontramos en Berceo, Milagros, aunque sin significado ("luzie como estrellas, semejant de luzero", 321d). Sin embargo, ya desde el siglo XIII parece que se usa preferentemente para el lucero matutino. Así lo veíamos en el texto de Alfonso X ; también parece deducirse del Libro de Alexandre: "Tardaua el luzero nos podie leuantar" (148v.). A. de Palencia lo indica en varias ocasiones ${ }^{55}$ : "esta estrella a la mañana se dize luzero. \& ala prima noche en poniendo se el sol: vespero." (253v.). También Nebrija hace referencia a la mañana: "Luzero estrella de la mañana". Incluso Autoridades parece darle ese mismo sentido: "La estrella que comúnmente se llama de Venus, precursora del día, quando antecede al sol. Sale del latino Lucifer que significa esto mismo."

Pero ya E. Terreros diferencia "Lucero de la mañana, Venus, la estrella que sale con la Aurora" y "Lucero de la noche o tarde, esta misma estrella, que queda muchas veces después del sol sobre el horizonte". Y significativa es también la distinción que este autor hace con estrella: "Estrella de Diana, llaman algunos a Venus, cuando sale por la mañana, tiempo en que también se le da el nombre de Lucero, y de Estrella del Alba. [...]. Por la tarde se llama esta misma estrella, estrella de la tarde, del Pastor y de Venus".

Sin embargo las formas complejas lucero de la mañana, lucero del alba, lucero del dia, aparecen también desde época temprana. Algunos ejemplos tenemos en:

“... o commo cayste de los çielos el luzero de la mañana tajado eres para la tierra sorteador o aflacador de las nasçiones" (Biblia romanceada judío cristiana).

"España fue antiguamente llamada esperia por la estrella de la mañana que luzero del alua llamamos" (Diego de Valera, Crónica de España, fol 21r.).

En las dos citas de la Celestina que aparece la lexía compleja (Zaragoza, 1507 y Valencia 1514), la utilización de una forma u otra parece venir determinada por la rima:

\footnotetext{
${ }^{55}$ A veces repitiendo las palabras del Rey Sabio: “... al salir del sol se dice luciferum luzero. \& al poner del sol vesperus o hesperus. dende hesperia se nombra españa” (fol 523v).
} 
“... ya quando veen salir el luzero del alua quiere se les salir el alma (F de Rojas, Tragicomedia ...., ed. 1507; fol. 17r.).

Estrellas que relumbrays / norte e luzero del día / por qué no le despertays / si duerme mi alegria" (Idem, 63v.).

Venus-Lucero de la tarde (ALEA, m. 841; ALEICan, m. 756; ALEANR, m. 1319; Cantabria, m. 48)

En algunos atlas, sobre todo en el de Andalucía, no aparece respuesta en varias de las localidades encuestadas. Ello se debe, según señalan los autores del ALEA, "a que este astro tiene para los campesinos mucha menos importancia que el lucero de la mañana". Sin embargo, sí parece tenerla para los cuidadores de ganado (vaqueros, pastores, etc.), tal como reflejan algunas de las formas encontradas en otras zonas. Las diferentes denominaciones recogidas son:

Venus: ALEA, Se 602; Ca 402; Co 400; Gr 400, 404; Al 201, 202, 203, 302, 400; ALEICan, $\mathrm{Lz} 1,3,4 ; \mathrm{GC} 12,3$; Tf 41, 50; Go 4. Y con la forma en - $o$ [beno] que indica el uso popular Lz 20; Fv 2, 3; GC 11, 30; ALEARN, Na 402.

Lucero: ALEA, H 101, 202, 203, 300, 301; Se 100, 102, 302, 305, 403, 503; Ca 301, 400, 600; Co 101, 104; Ma 406; Ja 102, 200, 204; 302, 300; Gr. 301, 304, 402, 512; Al 403, 500, 601. ALEICan, GC 20. Cantabria, S 107, 203, 210, 301, 302, 307, 310, 311, 401, 402, $408,503,601$

Lucero Venus: Se 404; Ca 500; Co 400; J 402 [1. beno], 403; Gr 403, 203; Al 600, 602, 301.

La estrella Venus: ALEICan, Gs; Lz 2, 10, 4; Fv 20, 31. [estrella beno] en GC 1.

Pero lo más general, al igual que veíamos antes, es la construcción formada por "lucero / estrella + de + sustantivo" en la que este último indica el momento del día o el lugar por donde se ve. Así

Lucero de la tarde: ALEA, H 100, 302, 400, 603; Se 200, 308, 406; Ca 200, 202, 205, 602; Co 102, 202, 602, 609; Ma 302, 402, 403, 405, 407, 501, 503, 600; J 201, 202, 304, 500; Gr 300, 309, 501, 504, 506, 509, 514, 515, 603, 604; Al 204. ALEICan, GC 10.

Lucero de la noche: ALEA, H 500 (con l. de la tarde) Co 604; J 203, 303, 307, 400 (con l. de la tarde), 600; Gr 408, 502, 600; Al 404, 405. ALEARN, Na 501, 502, 605; V 100; Te 103, 504.

Lucero del atardecer: ALEA, J 504

Lucero del anochecer: ALEA, H 602, Se 402, 501; J404. Cantabria, 308, 312, 313, 404.

Lucero del oscurecer: ALEA, Gr 203 (con el benu), 409, 512; Al 509

Lucero del poniente: ALEA, Co 401, 603; Ma 201. Cantabria, S 407, 409, 501, 502

Lucero de ponerse el sol: ALEA, Se 601. 
Lucero de la puesta del sol: ALEA, Se 301.

Lucero del sol: en ALEA, Ma 100, debe tratarse de una elipsis (o error?) de alguno de los anteriores.

Lucero de las doce: ALEA, J 305. El informante justifica el término "porque se pone a medianoche" 56

Lucero de la madruga(da): ALEA, Al 502. Aparece con interrogación, porque es lógico pensar que debía referirse al lucero del alba, como veíamos antes, pero éste en esa localidad es el "lucero de la mañana".

Lucero noveno: ALEA, Ca 201. El DRAE no recoge esta forma, pero sí Estrella nona: "1. Astron. estrella temporaria". Y a ésta la define como: "Astron. La que repentinamente adquiere un brillo superior al ordinario y lo mantiene durante cierto tiempo."

Estrella del poniente: ALEA, H 102.

Estrella de noche: Cantabria, S 305.

Lucero (estrella) de la noche: ALEANR, Na 501, 502; Te 103, 504; V 100.

(Lucero o estrella) de la vesprá : ALEANR,Te 204. Es el único derivado de VESPERU documentado en los atlas, y, como se ve, pertenece al dominio lingüístico catalán (con fonética valenciana).

Estrella del norte: Cantabria, S 306. ALEARN, Na 401. Es posible que estemos ante una confusión con la estrella Polar.

El astro del año: ALEA, J 501. Es el único ejemplo en el que en vez de lucero o estrella utiliza la denominación más general "astro". Y también el segundo elemento ofrece un significado amplio, pues aunque efectivamente es el único que se ve durante todo el año, sólo durante una época (ahora los siete primeros meses del año) es visible por la noche.

También encontramos otras construcciones más difíciles de explicar si tenemos en cuenta el significado del segundo elemento, como son:

Lucero del lubricán: ALEA, Ca 100, que hace suponer que se está refiriendo al crepúsculo vespertino. La Academia da para esta voz la escueta definición de "crepúsculo". Pero sabemos que en algunas zonas andaluzas lubrican significa "el anochecer, tiempo entre día y noche", como registraba ya F. Del Rosal.

Más extrañas por contradictorias en cuanto al significado son las perífrasis:

Lucero del alba (ALEA, Co 201$)^{57}$, Lucero del alba castellana (ALEANR, Z305) ${ }^{58}$, e incluso Lucero del alba de la noche (ALEA, Se 300; Co 302) ${ }^{59}$, que permiten pensar que

\footnotetext{
${ }^{56}$ Debido a las distancias de las órbitas de Venus y la Tierra desde el Sol, Venus sólo puede verse en los crepúsculos y generalmente nunca más de tres horas antes del amanecer o tres horas después del ocaso, lo que concuerda perfectamente con esa hora de la noche.
} 
en esos lugares el sintagma lucero del alba se ha lexicalizado sin distinción de mañana o tarde.

También tenemos el lucero de prima (ALEA, Ca 101), aunque en este caso es probable que no haya ninguna contradicción, dependiendo del significado de prima. Sí la habría si partimos de las dos primeras acepciones del DRAE: " 1 . $\mathrm{f}$. Primera de las cuatro partes iguales en que dividían los romanos el día artificial, y que comprendía desde el principio de la primera hora temporal, a la salida del Sol, hasta el fin de la tercera, a media mañana. 2. Una de las siete horas canónicas, que se canta a primera hora de la mañana, después de laudes.". Sin embargo también en el DRAE tenemos otro significado: "12. Mil. Primero de los cuartos en que para las centinelas se dividía la noche, y comprendía desde las ocho a las once", que ya aparecía en Nebrija (1495), de uso general: "Prima en la vela. vigilia prima". De manera que también puede referirse a la primera vigilia de la noche en otros ámbitos, como el marinero. Así recoge Figueiredo (1996) en portugués horas de prima: "Ant. A primeira vigia de noite, das 9 ás 11 horas, nos arriais e navíos". La localización de esta denominación en la costa gaditana (Chipiona), junto con astél de la prima en Peñiscola (Cs 1) y estel de se prime en Port de Sóller (Mall 1) (Alvar, 1985) nos permite pensar que también aquí se trata de una influencia del léxico marinero ${ }^{60}$.

Lo que ocurre es que también encontramos el lucero (d)el día (ALEA, H 504, 600; Se 405; Ca 203 (con lucero); Gr 307; Al 507), donde resulta más difícil justificar la lexicalización o, mejor dicho el desplazamiento significativo, e incluso estrella matutina (Ma 203) que igualmente hizo dudar a los autores del ALEA, colocando una interrogación tras la respuesta..

También puede equivocarse el planeta, pues en el ALEA aparece lucero marte (H 201), el planeta marte (Se 201) o simplemente marte (J 502) ${ }^{61}$.

El artillero [artiyero], el lucero: en ALEA, Se 100, viene a indicar que se ha producido un cambio léxico, de manera que la forma, por etimología popular, adecuada (y con cierta extensión en otras zonas andaluzas) para los astillejos (o constelación de los Gemelos) ha

\footnotetext{
${ }^{57}$ El de la mañana se denomina Lucero del día y miguero

${ }^{58}$ En esta misma población se recogí lucero del alba para la estrella de la mañana, por lo que la distinción es sumamente simple.

${ }^{59}$ También aquí se documentó lucero del alba, junto con lucero miguero para el de la mañana.

${ }^{60}$ Alfonso de Palencia, intentando dar la etimología dice "Hesperus en griego: en latín luzero por que pareçe agora prima noche: \& despues al alua del dia" (fol 192 r) (el subrayado es nuestro) de manera que también podría ser el resultado de una elipsis partiendo de "lucero de prima noche".

${ }^{61}$ El fenómeno no es exclusivo andaluz, pues en el Léxico de los marineros peninsulares (Alvar, 1985: 145) fue la respuesta en la localidad gerundense de Blanes (Ge 4 )
} 
pasado a ser sinónimo de lucero. Quizás por ello en esa localidad no hay respuesta a la pregunta correspondiente a esta constelación ${ }^{62}$ (ALEA, m. 842).

Otras denominaciones donde el segundo elemento pertenece a un campo semántico distinto son menos usuales. En Andalucía y Canarias encontramos algunas, aunque son más frecuentes en Aragón, sobre todo los compuestos formados con nombres de oficios o tareas relacionadas con el campo y especialmente con el ganado ${ }^{63}$. Entre ellas tenemos:

a) relacionadas con el trigo o similar

\section{Lucero del trigo: ALEA, Co 605}

Lucero del pan caro: ALEA; Ma 401. Aparentemente podría parecer una contradicción con la anterior. Sin embargo ambas denominaciones deben responder a la asociación de esta estrella con las buenas o malas cosechas, dependiendo del lugar (el este o el oeste) por donde aparezca cada año en la época de siembra y recolección (recordemos que Venus presenta, entre otras, la particularidad de girar en sentido inverso al de los demás planetas).

Lucero de las migas: ALEA, Co $607^{64}$

Estrella del gofio: ALEICan, LP 1, $10^{65}$.

b) con el agua:

El lucero del río: ALEA, J 401. Es debido a una tradición, ${ }^{66}$ señalada por el informante, según la cual si el lucero "camina sobre el cauce del Guadalquivir, será un buen año; pero malo si se desvía".

Estrella del agua: ALEICan, La isla de El Hierro completa; LP20; Tf3. El informante de Hi 1, 2 explica que se llama así porque llueve cuando llega al filo de la cumbre.

c) con oficios, referidos a labores muy concretas relacionadas con el campo o el ganado:

Lucero marranero: ALEA, Gr 401. En Gr 405 es estrella (d)el marranero.

${ }^{62}$ Vid. ALEA, m. 842. Es éste uno de los mapas donde la mayoría de las respuestas son un claro ejemplo de segundas etimologías o etimología popular, entre las que destacan la que acabamos de ver, junto con castillejos, castillero, rastrillejo, etc.

${ }^{63}$ Amades, J. (1982, vol. I, p. 82) hablando de la influencia de Venus dice que " La gent de munyanya el prenen per guia de l'hora d'engregar o de recollir la ramada, i la de la terra plana, així mateix com a anunci que els cal plegar de la feina, i d'ací que se'l distingeixi amb diversos noms, d'acord amb aquestes idees, i que hom el qualifiqui d' estel dels pastors, Estel del bovers, Estel dels porquers, Estel dels boters, i simplemente, de Pastor, Bover i Porquer.".

${ }^{64}$ Esta denominación es más usual en Andalucía para el 'lucero de la mañana', al que en esta población, según el informador, se denomina lucero del día y estrella del rabo.

${ }^{65}$ También esta denominación en la misma isla de La Palma se refiere al 'lucero de la mañana' (LP 3)

${ }^{66} \mathrm{La}$ relación de las estrellas con el río es bastante antigua, hasta el extremo de que el calendario astronómico de los egipcios tomaba como punto de partida la aparicion de la estrella Sirio en el horizonte, el 19 de julio, coincidiendo con los comienzos de la crecida del Nilo 
Estrella del pastor: ALEARN, Hu 405, 500. Cantabria, S 405.

Gayanera (con elipsis de estrella) en ALEICan, Fv 30 es probablemente el resultado de un proceso de disimilación de palatales a partir de gañanera ${ }^{f}$

Labradora : (Igualmente con elipsis de estrella) ALEICan (Go 3, 40) parece extraña, desde el punto de vista del significado y por cuanto en Go 4 es el nombre del lucero de la mañana. Sin embargo aquí la oposición se realiza a través de lucero / labradora, o sea al revés de como cabría esperar.

Los otros compuestos proceden todos del ALEARN y están formados con lucero o estrella seguidas de la preposición de (que puede elidirse) y un nombre de oficio relacionado cpn el ganado como son: borreguero (Lo 103, 400, 600, 602, 604); borreguera ( $\mathrm{Na} 308$ ); bovate $^{68}(\mathrm{Z} 606)$ boyero con distintas variantes: buayero $(\mathrm{Z} 402)$, goyeros (Hu 300), güeyero (Te 404), güeyeros ( $\mathrm{Z} 202)$, guayetero (Hu 305), guatero (Hu 407); majadero (Lo 500 ); porquero (Hu 207, 401) y la solución catalana porqué(r) (Hu 205, 404); vaquero (Te 307)

\section{Distribución dialectal}

Los atlas son muy escuetos en este caso. Sin embargo podemos concluir que también para "lucero de la tarde" se prefieren, en general, formas complejas. Si bien Andalucía y Cantabria utiliza fundamentalmente aquellas formas en las que el segundo nombre del compuesto se inscribe en la esfera semántica de los distintos momentos del día: tarde, noche, anochecer, etc.; mientras que el dominio navarroaragonés se decanta por los nombres de oficios, que tienen además alguna localización en Andalucía oriental y Canarias. Esta última destaca por la fuerte presencia de las formas académicas Venus y estrella (de) Venus, que tienen también presencia andaluza como Venus o con la forma Lucero Venus.

\section{Documentación literaria}

Remitimos a la forma anterior.

\section{CONCLUSIONES}

El sistema de denominación utilizado para referirse a los cuerpos celestes más conocidos nos muestra un amplio número de voces, de diversa procedencia y distinto grado de utilización, de manera que formas como carro, camino de Santiago, lucero, etc. aparecen repartidas por todo el dominio lingüístico. En unos casos como continuación (con las lógicas derivaciones formales) de otras voces más antiguas, procedentes de las lenguas clásicas, ya sea directamente o como calco lingüístico; en otros son creaciones romances, motivadas generalmente por factores de tipo extralingüístico, factores sociales, que unas veces afectan

\footnotetext{
${ }^{67}$ En GC 10, 20 gayania 'cobertizo para las vacas', gañanía (ALEICan; Corrales Zumbado, 1992)

${ }^{68}$ Aunque Alcover y Moll, s.v. bovater 3 dicen: "Estrel Bovater: nom vulgar del planeta Venus, quan surt a la matinada (Alcarràs, Massalcoreig)".
} 
a un ámbito muy extenso (incluidas otras lenguas romances), como Camino de Santiago, otras a zonas más reducidas "camino de los uveros", "carril de Santiago", etc.

En las creaciones romances predominan las formas compuestas (o sintagmas nominales), generalmente perífrasis que responden a la estructura "sustantivo + de + sustantivo" o "sustantivo + adjetivo", en las que el primer sustantivo se incluye en un campo léxico muy concreto, que de alguna manera ya aparecía en latín ( "carro", "carreta", etc.; "camino", "carrera", etc.; "lucero", "estrella", etc.), y el segundo elemento, que aporta el contenido significativo para el hablante, procede comúnmente del léxico agrícola y ganadero (comidas, trabajos, animales, utensilios, etc.), señala referencias espaciales o temporales (poniente, día, mañana, tarde, noche, etc), o pertenece al ámbito religioso o de las creencias (Santiago, San Pedro, etc.). La elección de unos u otros depende en algunas ocasiones de los distintos dominios dialectales, pero también de diferentes factores culturales y sociales. En cuanto al tipo de compuesto nos encontramos con una gran variedad que va desde los claramente endocéntricos como lucero o estrella de la mañana, hasta los que se pueden considerar totalmente exocéntricos, como camino de Santiago, por citar el más conocido.

\section{BIBLIOGRAFÍA}

Archivo digital de manuscritos y textos españoles (ADMYTE), II, Madrid, Micronet

AlCAlá VencesladA, A. (1951) : Vocabulario Andaluz, Madrid, Gredos

Alcover, M. y MOLl, F. de B. (1975): Diccionari català, valenciá, balear. Palma de Mallorca.

Alfonso X : Libros del saber de Astronomía. Manuscrito Complutense. Transcripción de Lloyd Kasten y John Nitti, en ADMYTE II. Transcripción inédita de Rafael Cáno Aguilar de los diferentes manuscritos.

Alfonso X : General Estoria. Transcripción de Lloyd Kasten, John Nitti, y otros autores, en ADMYTE II.

Alonso, M. (1986): Diccionario Medieval Español, Salamanca, Universidad Pontificia de Salamanca.

ALVAR, M. (1959): El español hablado en Tenerife, Anejo LXIX de la RFE, Madrid.

Alvar, M. (1975-78): Atlas Lingüístico y Etnográfico de las Islas Canarias. Las Palmas de Gran Canaria. Publicaciones del Excmo. Cabildo Insular. Citado ALEICan

AlvaR, M. (1985): Léxico de los marineros peninsulares, Madrid, Arco-Libros, 4 vols.

Alvar, M. (1995): Atlas Lingüístico y Etnográfico de Cantabria, Madrid, Arco - Libros.

Alvar, M., Llorente, A. Salvador, G. (1961-74): Atlas Lingüístico y Etnográfico de Andalucía, Granada, Universidad de Granada. Citado ALEA.

Alvar, M., Llorente, A., Buesa, T. y Alvar, E. (1979): Atlas Lingüístico y Etnográfico de Aragón, Navarra y La Rioja, Madrid, CSIC .Citado ALEANR.

AMADES, J. (1982): Costumari català, Barcelona, Salvat Editores.

ANDOLZ, R. (1977): Diccionario aragonés, Zaragoza, Librería General. 
Los nombres de los "cuerpos celestes" en los atlas...

ANÓNIMO: Biblia romanceada judio cristiana. Madrid, Academia de la Historia, Códice 87. Siglo XIV. En ADMITE II

COMAS SOLÁ, J. (1942): Astronomía, Barcelona, Editorial Labor.

- Corominas, J., Pascual, J. A. (1980-1991): Diccionario Crítico Etimológico Castellano e Hispánico, Madrid, Gredos. Citado DECH

BERCEO, G. De (1986) : El libro de los Milagros de Nuestra Señora, Edición crítica y estudio de J. Montoya, Universidad de Granada

Corrales zumbado, C., CORBella, D., y Álvarez, A. (1992): Tesoro Lexicográfico del Español de Canarias, Madrid, Real Academia

Covarrubias, S. DE (1977): Tesoro de la Lengua Castellana o Española, Madrid, Ediciones Turner.

- Diccionario General de la lengua española Vox (1997), Madrid, Bibliograf

FÉRNANDEZ GOMEZ, C. (1962): Vocabulario de Cervantes, Madrid, Real Academia Española.

FÉRNANDEZ GómEZ, C. (1971): Vocabulario de Lope de Vega, Madrid, Real Academia Española.

FERNÁNDEZ DE SANTAELLA, R. (1999 [1499]): Vocabulario eclesiástico, Sevilla. En ADMITE II

FIGUeIREDO, C. DE (1996): Novo dicionário da lingua portuguesa, Lisboa, Bertrand Editora.

$>$ GARCÍA SORIANO, J. (1980): Vocabulario del dialecto murciano, Murcia, Editora Regional de Murcia.

GARULO, T. (1983): Los arabismos en el léxico andaluz, Madrid, Instituto Hispano-Árabe de Cultura.

Gongora, L.(1921 ): Obras poéticas de D. Luis de Góngora, New York, The Hispanic Society of america, vol I. Y en ADMITE II

Grimal, P. (1973): Mitologías. Del Mediterráneo al Ganges, Barcelona, Planeta, 2 vols.

Gutí́RreZ TUÑón, M. (1996): Atlas Lingüístico de El Bierzo, Instituto de Estudios Bercianos, vol I. Citado ALBI

Herrera, G. A. (1988 [1513]): Agricultura General. Ed. de Eloy Terrón, Madrid, Ministerio de Agricultura.

IsIDORO, SAN, ARzobispo De Sevilla (1993): Etimologías. Edición bilingüe de J. Oroz Reta y M. A. Marcos Casquero. Madrid, Biblioteca de Autores Cristianos.

JiMÉNEZ, J. R. (1917): Platero y yo, ed. de M. P. Predmore, Madrid, Cátedra, 1996.

LERNER, I. (1974): Arcaísmos léxicos del español de América, Madrid, Ínsula

Machado, J. P. (1967): Diccionario Etimologico da Lingua Portuguesa, Lisboa

Miguélez RodrígueZ, E. (1993): Diccionario de las hablas leonesas (León, Salamanca, Zamora), León. 
MOLINER, M. (1967 y 1998): Diccionario de uso del español, Madrid, Gredos.

Morínigo, M. A. (1993): Diccionario del español de América, Madrid, Anaya \& Mario Muchnik

NebridA, E. A.(1989 [1495]): Vocabulario español-latino, edición de la Real Academia Española, Madrid. Y en ADMITE II.

NEBRUA, E. A.(1999 [1492]): dictionarium latino- hispanicum . En ADMITE II

OUdIN, C. (1968 [1675]): Tesoro de las dos lenguas española y francesa, Ed. Facsímil, Paris, Ediciones Hispanoamericanas.

PALENCIA, A. DE (1957 [1490]): Universal vocabulario de Alfonso de Palencia, Madrid, Real Academia Española, edición de J. M. Hill. Y en ADMITE II.

PALUZIE Borrell, A.(1979): Astronomía. Explorando el Universo, Barcelona, Ramón Sopena.

Real Academia Española (1960 y ss.): Diccionario Histórico de la Lengua Española, Madrid

Real ACAdEMia EsPañola (1970, 1984,1992): Diccionario de la lengua española, Madrid, Espasa-Calpe.

Real Academia Española (1984): Diccionario de Autoridades, Madrid, Gredos.

- Real Academia Española (1989): Diccionario Manual e Ilustrado de la Lengua Española, Madrid, Espasa-Calpe.

RoJAS, F. DE (1999 [1507, 1514]): Tragicomedia de Calisto y Melibea, Zaragoza, Jorge Coci, 1507; Valencia, Juan Joffre, 1514. En ADMITE II; y Edición crítica de M. Criado de Val y G. D. Trotter.

RosAl, F. DEL (1992): Diccionario Etimológico, Madrid, Consejo Superior de Investigaciones Científicas, edición facsimilar y estudio de E. Gómez Aguado.

SÁNCHEZ- BOUDY, J. (1978): Diccionario de cubanismos más usuales, Miami, Florida.

Santamaría, F. J. (1942): Diccionario General de Americanismos, México D. F.

TALLGREN, O. J. (1925): "los nombres árabes de las estrellas y la transcripción alfonsina", en Homenaje a Menéndez Pidal, Madrid, vol II.

a TERREROS, E. DE (1987): Diccionario Castellano con las voces de ciencias y artes, Madrid, Arco-Libros.

TORO Y GiSBERT, M. DE (1920): "Voces andaluzas o usadas por autores andaluces que faltan en el diccionario de la Academia", Revue Hispanique, vol. XLIX, pp. 313647.

VAlera, D. DE (1999 [1482]): Crónica de España, Sevilla, Alfonso del Puerto. En ADMITE II.

Velasco, E. y Velasco, P. (1999): Guía del cielo, Madrid, Procivel.

VIUDAS, A. (1980): Diccionario Extremeño, Cáceres, Universidad de Extremadura.

WEBB, E. J. (1957): Los nombres de las estrellas, México, Fondo de Cultura Económica. 